\title{
Effectiveness of Integrated Soft Tissue Mobilization on the Functional Outcome in Chronic Low Back Pain Patients
}

\author{
Antony Leo Aseer. $\mathbf{P}^{1}$, Iyer Lakshmi, Subramanian ${ }^{2}$ \\ ${ }^{\mathbf{1}}$ Reader in Physiotherapy, Sri Ramachandra University, Chennai, Tamilnadu \\ ${ }^{2}$ Faculty of Physiotherapy-Sri Ramachandra University, Chennai, Tamilnadu
}

\begin{abstract}
The experimental study is aimed to analyze the effectiveness of integrated soft tissue mobilization on the pain, lumbar spine mobility and the outcome on functions in chronic low back pain (CLBP). Irrespective of low back pathologies, soft tissues are vulnerable for dysfunction and paves way for pain-spasm vicious cycle. Very few studies in CLBP are being performed to explore its effect and integrated approaches in soft tissue mobilization were not studied. Totally sixty participants were randomized into control and experimental groups in the present study. Baseline measurements of pain severity, lumbar spine mobility and Oswestry disability Index (ODI) were measured. The control group received treatment in the form of strengthening program and stretching maneuvers. The experimental group received the all form of soft tissue mobilization. After three weeks of follow up, all the measurements were taken again. The experimental group showed significant improvement as compared to the control group in terms of lumbar spine mobility, reduction of disability and moderate improvement in pain severity. This study adds the importance of integrated soft tissue mobilization in recovery from CLBP. It further establishes soft tissue mobilization as a part of functional mobilization in rehabilitating CLBP.
\end{abstract}

Keywords: chronic low back pain, soft tissue mobilization, lumbar spine mobility, ODI

\section{Introduction}

The commonest symptom in musculoskeletal pathologies is low back pain and is considered as a most common health disorder in modern society. The causes include a wide variety of pathologies of lumbar spine and surrounding structures. Research by Anderson suggests that 70 to $85 \%$ of the population will come across low back pain at least once in their lives. Almost $90 \%$ of the acute low back pain show better improvements regardless of the therapy; remaining $10 \%$ are prone to develop chronic low back pain. Overall $90 \%$ of social costs are accounted for low back disorders (Anderson, 1996). This is one of the causes for long term absenteeism from work (Hazard, 1996) increased loss of work, sickness compensation, long term disability for long periods, need for social support and a functional restoration programs.

Depending on the duration of symptoms, low back pain can be classified as acute, sub-acute or chronic. According to European guidelines, chronic low back pain is defined as low back pain and discomfort, located below the costal margin and above the inferior gluteal folds, with or without radiating leg pain, persisting for a minimum of 12 weeks (Airaksinen, 2004). The $2^{\text {nd }}$ most known 
reason to visit the physician is noted to be chronic low back pain (Hart, 1995 \& Swedlow, 1992). In India, approximately $35 \%$ people suffer from chronic back pain (Andersson, 1999).

The lumbosacral region consists of 5 lumbar vertebrae and 5 sacral vertebrae fused together. These structures are an important weight bearing components supporting the trunk and upper body in postures of sitting, standing. The lumbar region is structured is such a way so as to provide maximum mobility of the spine. In order to protect the structures around this region, many ligaments and muscles surround it. The important structures in stabilizing the lumbosacral region include the erector spinae group, mutlifidus, abdominals, thoracolumbar fascia, iliopsoas and gluteus medius. The thoracolumbar fascia is an important passive structure which runs along the length of the back and provides stability during contraction of various groups of muscles at the back.

The four primary soft tissues of the body are epithelial, muscular, nervous and connective tissue. All these soft tissue structures have individual and unique functions which, when integrated work as a dynamic biomechanical unit (Keller, 1999). Grieve (1981) has emphasized that these structures are functionally interdependent upon each other. Grieve also states that most abnormalities presenting as joint pain may be the expression of an underlying imbalance of the whole musculoskeletal system, i.e., articulation, ligaments, muscles, fascial planes and inter muscular septa, tendons and aponeurosis.
For chronic low back pain a model proposed by Helene Langevin et al in 2006 is pathophysiological model, which suggests a multivariate causes and pathological process is complex in chronic low back pain. The several models of abnormal movement patterns include that of pain - spasm -pain model by Roland (1986) and pain adaptation model describing selective increased activity of antagonist muscle causing decreased range of motion by Lund (1991). The pain spasm pain cycle is a protective mechanism of the body to injury (Scott, 2004). Due to injury the nociceptors around the injured area get stimulated and send signals to the brain via the spinal cord where pain is perceived. Thus the brain sends signals to the surrounding muscles to contract in order to protect the area. This constant muscle contraction causes a decrease in circulation causing hypoxia due to the lack of blood circulation and oxygen and tissue damage. This leads to muscle spasm which further increases pain. This study suggests that abnormal movement patternshypomobility or hypermobility leads to fibrosis of connective tissue directly or indirectly via injury and inflammation respectively. The pathological changes in a muscle, during the initial phases of immobilization is shortening of muscle and associated connective tissue leading to true shortening of the muscle fibers. Hence, they propose that due to the limited activity in chronic low back pain, connective tissue fibrosis leads to altered muscle activation patterns, muscle spasm, neutrally mediated inflammation and micro trauma. The altered mechanical loads lead to the connective tissue plasticity causing 
fibrosis in connective tissues like ligaments and joint capsules.

Mostly chronic low back pain without specific pathological changes suffer from musculoskeletal dysfunction and treating these disturbances causes decrease in pain in many (Rosomoff, 1989). With the above beliefs one can conclude that whatever may be the reason of chronic low back pain, the ultimate brunt bearer are the soft tissue structures which need to be addressed during the due course of treatment.

With the advent of physiotherapy, many tried to find out the effects of conventional therapy as against surgical treatment to treat chronic low back pain. The studies finding the efficacy of modalities in chronic low back pain, include transcutaneous electrical nerve stimulation (TENS) (Lucie, 1991 \& Marchand, 2003), interferential therapy (Werners, 1999), laser (Bjordal, 2003) and short wave diathermy (Sweetman, 1993). Many of those disabled with chronic low back pain do seek for treatment. Although many treatment modalities do promise relief of pain, not much evidence is present as to its true potential in relieving and curing the disability. With the question of immobilization during rehabilitation; many concluded the beneficial use of exercises (Hagen, 2000, Kuukkanen, 2000, Mannion, 2001, Moseley, 2002, Peterson, 2002, Aure, 2003, Liddle, 2004, Jousset, 2004, Niemisto, 2003 \&). Interest then emerged in the role of manual therapy, mobilization and massage (Furlan, 2002, Hemmila, 2002, Aure, 2003, Cherkin, 2003, Chiradejnant, 2003, Harvey, 2003,
Licciardone, 2003, Walach, 2003, Assendelft, 2004, Jette, 2006).

Manual medicine or therapy infers to hands on treatment which includes gentle stretching of joint or mobilization to improve spinal joint mobility (Greenman, 1996). The effects of massage in nonspecific low-back pain was studied by Furlan et al (2010), who concluded that massage might be useful in sub-acute and non-specific chronic low-back pain patients. The primary purpose of these approaches is to treat symptomatic soft tissues. Soft tissue mobilization offers a functional approach, ultimately improving the patients' capacity to maintain balanced posture and improving body mechanics. The integrated approach encompassing evaluation of soft tissues system and application of specifically directed manual therapy techniques to facilitate normalization of soft tissue dysfunction is called functional mobilization (Pustaver, 1995). Soft tissue techniques causing mechanical stretching of the soft tissues, leading to connective tissue remodeling, encouraging circulation, enhancing venous and lymphatic return, also showing neurologic effects of release of endogenous opioids thus relieving musculoskeletal pain. To intervene specific musculoskeletal dysfunctions, manual treatments along with tailored exercises are in need (Bookhout, 1996).

An experimental study conducted by Geisser et al in 2005, aimed at examining the efficacy of manual therapy with specific exercise program for treating CLBP and disability. The tailored exercise program was compared with nonspecific program comprising stretching of soft tissues, aerobic fitness and manual 
therapy. Manual therapy with specific exercise reported better results and further studies are needed to examine the effects on improved function.

Evidences suggest that manual therapy and specific exercises showed positive impact in pain and disability. But no such evidence has specified the effects of manual therapy alone. Also several studies have analyzed few soft tissue structures but lack an integrated approach considering the skin, fascia, muscle, connective tissue, and neuromuscular component.

With the above views, emphasizing the need for further research, this study aims at analyzing the effectiveness of integrated soft tissue mobilization on the pain, mobility and functional outcome in chronic low back pain patients.

\section{Materials and Methods}

The experimental study was approved by the ethics committee of Sri Ramachandra University.

Study participants: Patients coming to the outpatient physiotherapy department of Sri Ramachandra Hospital were included. Chronic low back pain patients referred for physiotherapy by the orthopedic department were considered. Patients diagnosed as having low back ache for more than 3 months of duration with age group between 18 to 45 years were recruited. Subjects with previous spinal surgeries, neurological disorders, congenital spinal conditions and Spondyloarthropathies were excluded.

Study design \& Size: Randomized control trial and using a two sample comparison of means needed sample size of 70 subjects. To account for possible loss, 60 subjects were recruited. Simple randomization method was used to allocate the subjects into two groups, namely the control group and the experimental group.

Outcome measures - The baseline measures includes, visual analogue scale (VAS) - Self-report of rating scale of pain intensity of their average or usual pain. VAS has good reliability and concurrent validity when compared to other methods (Donald, 2003). Modified Schober's test (MST) was used to measure lumbar spine mobility of flexion and extension measures in pre and post treatment period as a measure of functional mobility. (Macrae, 1969, Domjan, 1990).

The revised Oswestry Disability Index (ODI) by Davidson et al (2002) was used as a functional outcome measure. This is a self-report questionnaire; the patient is instructed to fill it out. The patient follows the general instructions given at the top of the questionnaire. Each section had 6 possible answers. Statement 1 was graded as 0 point; statement 6 was graded as 5 points. A score of 50 was considered to indicate $100 \%$ disability. The disability scores between 0\%-20\% denoted minimal disability, $20 \%-40 \%$ denoted moderate disability, 40\%-60\% indicate severe disability, $60 \%-80 \%$ denotes crippled and $80 \%-100 \%$ denotes bedriden status.

A total of 77 subjects enrolled for the study. Of these, 7 subjects refused to participate, 10 subjects were not regular until follow up. After recruitment on eligibility, informed consent was obtained on explaining the treatment to be given. All subjects were given self-report measures and outcome measures. Subjects in the control group received exercises which included core strengthening of the 
lumbo-pelvic complex (Sahrman, 2002 \& Bookhout, 1997) includes abdominal progression; hip extensor in prone, hip abductor and external rotator training in side lying, multifidus strengthening and stretching exercises. The stretches included quadriceps, lumbar extensors, hamstring and prone lying on elbows.

The experimental group received an integrated Soft tissue mobilization including muscle energy technique, trigger point release, myofascial release, thoracolumbar lateral, longitudinal stretch, deep longitudinal inhibitory pressure. Trigger points were released by applying deep pressure with the thumb/ olecranon process at the tender points along the piriformis and gluteus medius muscles and pressure was gradually released as pain reduced. Post isometric relaxation was taught by asking the patient to contract the back extensor muscles isometrically in supine position and then relaxing it. Mechanical stretching was done by thoracolumbar lateral, longitudinal stretch given to the patient in prone position. Thoracolumbar deep pressure with thumbs or thumb reinforced by hand given over the involved muscle. Each patient in the experimental group was treated with soft tissue mobilization three times in a week.

Both the groups were given a pain relief modality given to the patients as a usual treatment approach in the outpatient department. Exercises were continued as a home program and reviewed regularly. After three weeks, follow up of the selfreport measures and outcomes were administered.

The data collection started at baseline comprising of the patient profile, pain severity using VAS, functional mobility of the patient using MST and ODI questionnaire. Post intervention values were got after three weeks of intervention. The process of data analysis consisted of baseline comparison between the control and the experimental groups, post treatment assessments between the groups, pre and post treatment comparison of various variables in the control and the experimental group.

\section{Results \& Discussion}

The effectiveness of integrated Soft tissue mobilization on pain, functional mobility and functional outcome was analyzed using inferential statistics (twotailed test). The data analysis was done using SPSS and statistical significance level was set. In the study, sixty participants participated of which 19 were males and 41 were females. All the 60 subjects were followed up till the end of the study (each group $n=30$ ). All the participants were regular for follow up and there is no missing data. In the control group 11 participants were male and 19 participants were females with a mean age of $35.57 \mathrm{yrs}$. In the experimental group 8 males and 22 females participated with the mean age of 36.03 yrs (Table 1). Overall $31.7 \%$ of males and $68.3 \%$ of females participated in the study.

Table-1 Patient demographics

\begin{tabular}{|c|c|c|c|c|c|}
\hline & GROUP & $\mathbf{N}$ & Mean & SD & SEM \\
\hline \multirow{2}{*}{ AGE } & Control & 30 & 35.57 & 7.718 & 1.409 \\
\hline & Experimental & 30 & 36.03 & 7.779 & 1.420 \\
\hline
\end{tabular}


Table- 2 Gender distribution between groups

\begin{tabular}{|c|c|c|c|c|c|}
\hline & & & & ROUP & \\
\hline & & & Contrl & Expmntl & Total \\
\hline Gender & Male & $\mathbf{N}$ & 11 & 8 & 19 \\
\hline & & $\%$ & 36.7 & 26.7 & 31.7 \\
\hline & Female & $\mathbf{N}$ & 19 & 22 & 41 \\
\hline & & $\%$ & 63.3 & 73.3 & 68.3 \\
\hline Total & & $\mathbf{N}$ & 30 & 30 & 60 \\
\hline & & $\%$ & 100.0 & 100.0 & 100.0 \\
\hline
\end{tabular}

Table- 3a - Pre (VAS_1) and Post (VAS_2) Comparison of VAS in the control group

\begin{tabular}{rllllll}
\hline Mean & N SD & $\begin{array}{l}\text { Mean } \\
\text { Diff. }\end{array}$ & T & p \\
\hline VAS_1 & 6.67 & 30 & 1.446 & $\begin{array}{l}2.10 \pm \\
1.54\end{array}$ & 7.47 & .000 \\
VAS_2 & 4.57 & 30 & 1.547 & & & \\
\hline
\end{tabular}

Table 3b: Pre (VAS_1) and Post (VAS_2) Comparison of VAS in Experimental Group

\begin{tabular}{|c|c|c|c|c|c|c|}
\hline & Mean & $\mathbf{N}$ & SD & $\begin{array}{l}\text { Mean } \\
\text { Diff. }\end{array}$ & $\mathbf{T}$ & $\mathbf{p}$ \\
\hline VAS_1 & 6.77 & 30 & 1.501 & $\begin{array}{l}1.63 \pm \\
1.37\end{array}$ & $\begin{array}{l}6.5 \\
0\end{array}$ & $\begin{array}{l}.00 \\
0\end{array}$ \\
\hline VAS_2 & 5.13 & 30 & 1.548 & & & \\
\hline
\end{tabular}

The mean value for pain severity (VAS) for the control group was 6.67 and after intervention the mean value of VAS was 4.57. The pain severity noted to be declined with a difference of 2.10. The mean value for pain severity (VAS) for the experimental group was 6.77 and after intervention the mean value of VAS was 5.13.The pain severity was observed to decline significantly with a mean reduction of $1.6 \quad(p=0.000)$. Compared to the experimental group, control group showed greater improvement in pain severity as evidenced by mean reductions in VAS scores.

Table-4 (a) Lumbar flexion range in the control group

\begin{tabular}{lllll}
\hline & Mean & N & SD & SEM \\
\hline MS_FLEXION_1 & 4.87 & 30 & 1.306 & .238 \\
MS_FLEXION_2 & 6.00 & 30 & 1.313 & .240 \\
\hline
\end{tabular}

The functional mobility tested by
MST in the control group showed a mean flexion of 4.87 pretest and 6 in post-test showing a significant increase $(\mathrm{p}=0.000)$.

Table-4 (b) Lumbar flexion range in Experimental group

\begin{tabular}{lcccc}
\hline & Mean & N & SD & SEM \\
\hline MS_FLEXION_1 & 5.67 & 30 & 1.155 & 0.211 \\
MS_FLEXION_2 & 6.37 & 30 & 1.377 & 0.251 \\
\hline
\end{tabular}

The experimental group showed a mean of 5.67 before and 6.37 after intervention in the range of flexion with a significant difference. $(\mathrm{p}=0.000)$. Overall the lumbar flexion range has improved in experimental group than control group.

Table-5 (a) Lumbar extension range in Control group

\begin{tabular}{lcccccc}
\hline & Mean N & SD & Mean Diff. & T & p \\
\hline MS_EXTENSION_1 & & & & & & \\
& 3.77 & 30 & .935 & $-.533 \pm 1.106$ & -2.64 & .01 \\
MS_EXTENSION_2 & 4.30 & 30 & .988 & & &
\end{tabular}

The ranges for extension showed a mean extension of 3.77 before and 4.30 after intervention in control group $(\mathrm{p}=0.013)$.

Table-5 (b) Lumbar extension range in Experimental

\begin{tabular}{|c|c|c|c|c|c|c|}
\hline & Mean & $\mathbf{N}$ & SD & Mean Diff. & $\mathbf{T}$ & $\mathbf{p}$ \\
\hline MS_EXTENSION_1 & 3.10 & 30 & 1.125 & $\begin{array}{c}- \\
.333 \pm 0.479\end{array}$ & $\overline{3.81}$ & .001 \\
\hline MS_EXTENSION_2 & 3.43 & 30 & 1.194 & & & \\
\hline
\end{tabular}

In the experimental group the mean extension before intervention was observed to be 3.10 and after intervention 3.43 with a significant mean difference of $0.333 \pm .479(\mathrm{P}<0.001)$. On comparing the experimental group, control group was found to show minimal improvement in the lumbar extension range.

Table-6 (a) Oswestry Disability Index (ODI) in the control group

\begin{tabular}{lllllll}
\hline & Mean & N & SD & Mean diff. & T & P \\
\hline ODI_1 & 20.93 & 30 & 6.378 & & & 7.323 \\
ODI_2 & 14.50 & 30 & 6.061 & $6.433 \pm 4.812$ & & \\
\hline
\end{tabular}


The measures of ODI showed a mean value of 20.93 before intervention and 14.50 after the follow up, with mean difference of $6.433 \pm 4.812(\mathrm{p}=0.000)$.

Table-6 (b) Oswestry Disability Index in the Experimental group

\begin{tabular}{lllllll}
\hline & Mean N & SD & $\begin{array}{l}\text { Mean } \\
\text { difference }\end{array}$ & T & P \\
\hline $\begin{array}{l}\text { ODI_ } \\
1\end{array}$ & 23.90 & 30 & 7.635 & $8.167 \pm 5.931$ & 7.542 & .000 \\
$\begin{array}{l}\text { ODI_ } \\
2\end{array}$ & 15.73 & 30 & 7.230 & & & \\
\hline
\end{tabular}

The experimental group showed a mean ODI value of 23.90 before the intervention and 15.73 after the intervention with a mean difference of $8.167 \pm 5.931 \quad(\mathrm{p}=0.000)$. Overall, the functional outcome of ODI values shows reduction in the disability index in the experimental group than the control group.

Table- 7 (a) Measures of disability in control group

\begin{tabular}{llllll}
\hline Mean & N & SD & $\begin{array}{l}\text { Mean } \\
\text { difference }\end{array}$ & T & P \\
\hline D_1 41.87 & 30 & 12.757 & $12.867 \pm 9.623$ & 7.323 & 0.000 \\
D_2 29.00 & 30 & 12.123 & & \\
\hline
\end{tabular}

The measure of disability calculated with the help of ODI shows a mean value of 41.87 pre-test and 29 post-test in the control group. The mean difference is $12.867 \pm 9.623(\mathrm{p}=0.000)$.

Table-7 (b) Measures of disability in experimental

\begin{tabular}{llllllll}
\multicolumn{8}{c}{ group } \\
\hline & Mean & N & SD & $\begin{array}{l}\text { Mean } \\
\text { difference }\end{array}$ & T & P \\
\hline D_1 & 47.80 & 30 & 15.271 & & & .000 \\
D_2 & 31.00 & 30 & 14.797 & $16.800 \pm 12.280$ & 7.494 & \\
\hline
\end{tabular}

In the experimental group the mean value of disability is 47.80 before and 31.00 after the intervention with mean decrease of $16.800 \pm 12.280 \quad(\mathrm{p}=0.000)$. The disability measures in the experimental group are lower, when compared to control group.

Table-8 (a): Disability grade (pre test) in the control and the experimental group

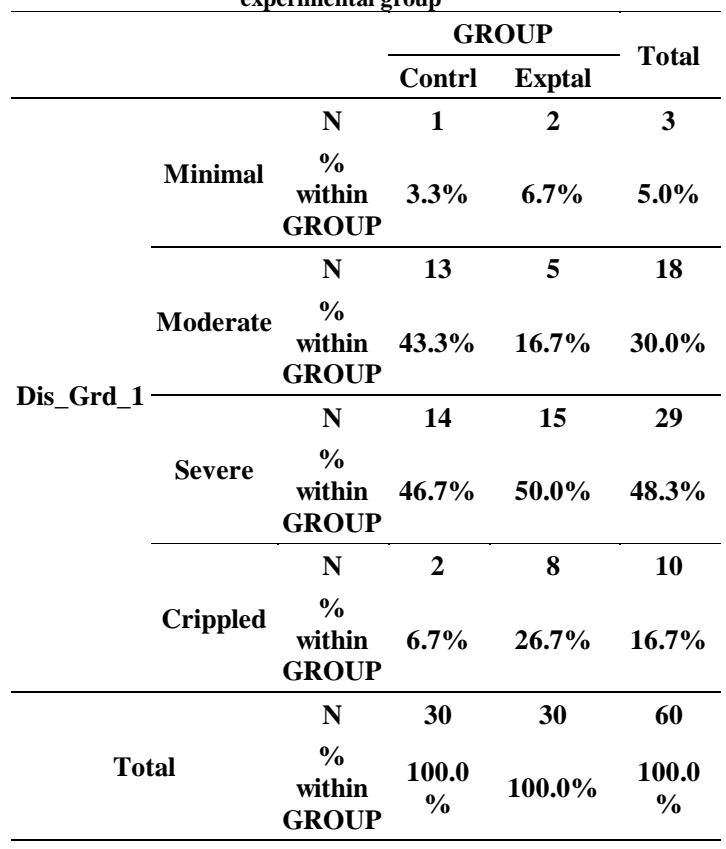

The disability grade distributions in both groups are two participants in the control group are in crippled category and 8 participants in the experimental group. One in the control group and two subjects in the experimental group are in minimal disability category while in the moderate disability category 13 in the control group and 5 in the experimental group. Similarly in severe disability category 14 subjects in the control group and 15 in the experimental group were observed. No subjects were reported in the bedridden category.

Table-8 (b) Disability grading (post test) in control and experimental group

\begin{tabular}{llcccc}
\hline & & \multicolumn{3}{c}{ GROUP } & Total \\
& & Contrl & Exptal & \\
\hline Dis_Grd_2 & Minimal & N & 7 & 8 & 15 \\
\hline
\end{tabular}




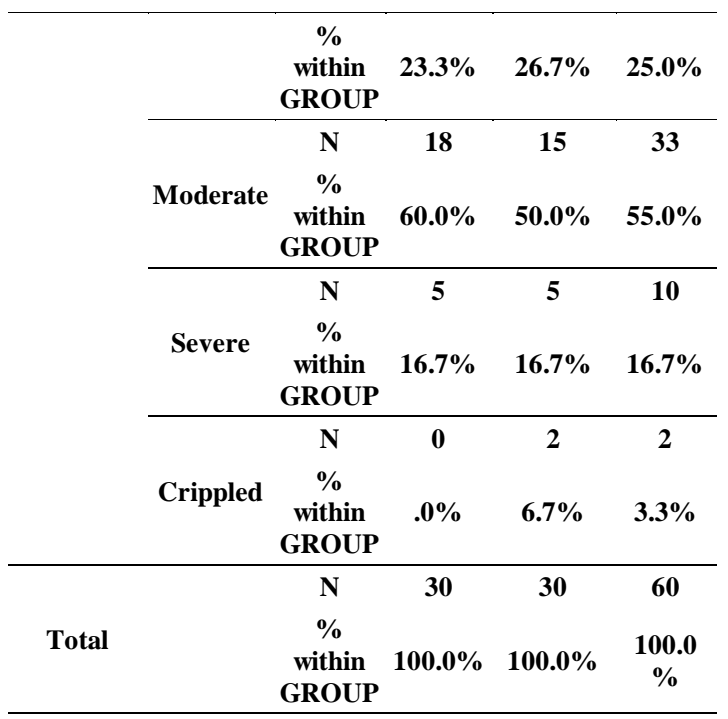

The disability grade distributions in both groups are as follows. Two participants in the control group are in crippled category as compared to 8 participants in the experimental group. One in the control group and two in the experimental group are observed in minimal disability category. In the moderate disability category 12 subjects were observed in the control group and 5 in the experimental group while in the severe disability category 14 in the control group and 29 in the experimental group. No subjects were observed to belong in the bedridden category.

The experimental study analyzed the effectiveness of integrated Soft tissue mobilization on the functional outcome of chronic low back pain patients, noted to have decrease in pain score (VAS) in both the control and the experimental groups. Many studies have shown the effects of exercises in pain decrement and functional improvement in chronic low back pain as against treatment received by a general practitioner. Though conflicts do exist with this thought; the European guidelines suggest that exercises along with usual physiotherapeutic methods are efficient in the rehabilitation of chronic low back pain. The study results also support a reduction in pain and improved spinal mobility. There was reduction of pain and improved functional mobility in the experimental group that is, those who received soft tissue mobilization. Gert Bronfort et al in 2003 suggested mobilization can be an option for the treatment of both low back pains after a systemic review conducted among ten randomized control trials. The guidelines further suggest that there is limited evidence of combined therapy of massage with remedial exercises and education for pain relief and functional improvements. Even though the results show a mean of $2.10 \pm 1.54$ in pain, $1.133 \pm .819$ in flexion and $-0.533 \pm 1.106$ in the extension ranges in the control group; mean of $1.63 \pm 1.37$ in pain and $.700 \pm 1.055$ in flexion and $-0.333 \pm .479$ in extension ranges in the experimental group. There was a significant difference in the results of pain and functional mobility within the experimental group. This agrees with similar finding reported in previous studies done by Gert Bronfort et al (2003) that concluded little evidence that back exercise is superior to mobilization. The functional performance of the patients checked by Oswestry Disability Index showed a mean difference of $6.433 \pm 4.812$ in the control group and $8.167 \pm 5.931$ in the experimental group. Gronbald et al (1997) tried to find out the interrelationship between spinal movements, performance tests, pain severity and disability evaluation. They concluded that there is moderately 
significant $(\mathrm{p}<0.01)$ inverse correlation between disability evaluation and in all performance tests in women population. This could be a cause for not having a similar correlation with functional outcomes of modified Schobers Test and that of Oswestry Disability Index.

The oswestry disability index includes basic functional assessment of movements. The process involved comparing the original performance of various tasks with noted restriction on corresponding subsections. A factor-analytic study was also undertaken by Fisher \& Johnston (1997) determined two specific factors of disability and changes in the disability were reliably measured by the Oswestry Disability Questuinnaire.

Francisco el al (2004) conducted a correlational study and concluded clinically significant decrement in pain leading to almost recognizable changes in disability and quality of life. Similarly in the present study, \% of disability with ODI, there was a drastic change in disability progressing from crippled to severe- moderate- minimal disability in both control and experimental groups. The number of subjects in the crippled category reduced from 2 to 0 in the control group and from 8 to 2 in the experimental group after intervention. In the severe category the number of subjects decreased from 14 to 5 in the control group and from 15 to 5 in the experimental group. The number of subjects increased in both minimal and moderate category after intervention in both the control and experimental groups. The progression towards lesser disability was seen more in the experimental group. Hence, the integrated soft tissue mobilization showed better functional outcome in chronic low back pain subjects.

Soft tissue techniques although used in practice by therapists, this integrated approach encompassed techniques addressing all soft tissue structures involved in the pathophysiology of back pain. Soft tissue mobilization addresses a more efficient biomechanical function because of release of fascial tension (Ganong, 1978). It also provides local and general vascular changes in the vascular and lymphatic circulation. Another model proposes that soft tissue techniques lead to connective tissue remodeling, encouraging circulation, enhancing venous and lymphatic return, also showing neurologic effects of release of endogenous opioids thus relieving musculoskeletal pain. These physiological models suggest the importance of implementing soft tissue techniques in rehabilitating chronic low back pain. Even though the intervention is for shorter duration, the functional outcome in the interventional group showed better improvements. The functional outcomes are the overall indicators and it is considered to be an ultimate outcome in any rehabilitation.

Hence, considering the above physiological factors, importance of manual techniques, the results of the study seems to be justified. Soft tissue mobilization to the low back region can thus help in providing pain relief, mobility and functional improvement. The limitations include a relatively smaller sample size in order to make the results more valid and long term effects need to be monitored. As not much has been studied 
related to the integrated soft tissue mobilization techniques towards outcomes of pain, mobility within a larger population of low back pain, there is much scope in future to establish this through research. Integrated soft tissue mobilization forms an integral component in rehabilitation of chronic low back pain with optimal duration of training.

Conclusion: The experimental study on the effects of integrated soft tissue mobilization in chronic low back pain subjects revealed a decrement in pain, lumbar mobility and the overall functional outcome in both the groups. In specific, integrated soft tissue mobilization group showed a moderate improvement in the functional outcome than the control group. The integrated soft tissue mobilization plays an integral component in the intervening chronic low back pain.

\section{References}

Airaksinen, J.I., Brox, C., Cedraschi, J., Hildebrandt, J., Klaber-Moffett, F. Kovacs, A.F., Mannion, S. Reis, J.B. Staal, H. Ursin, G., Zanoli. 2006. European guidelines for the management of chronic non-specific low back pain; Low back pain: guidelines for its management. Europ. Spine Journal; suppl 2:S 192-300.

Andersson, G.B.J. 1999. Epidemiological features of chronic low-back pain. Lancet, 354: 58185 .

Assendelft, W.J., Morton, S.C., Yu, E.I., Suttorp, M.J., Shekelle, P.G. 2003. Spinal manipulative therapy for low back pain. A meta-analysis of effectiveness relative to other therapies. Ann. Intern. Med., 138(11): 871-81.

Assendelft, W.J., Morton, S.C., Yu, E.I., Suttorp, M.J., Shekelle, P.G. 2004. Spinal manipulative therapy for low-back pain (Cochrane Review). In: The Cochrane Library, Issue 3. John Wiley \& Sons, Chichester, UK.

Aure, O.F., Nilsen, J.H., Vasseljen, O. 2003. Manual therapy and exercise therapy in patients with chronic low back pain: a randomized controlled trial with 1-year followup. Spine, 28(6): 525-31.

Bjordal, J.M., Couppe, C., Chow, R.T., Tuner, J., Ljunggren, E.A. 2003. A systematic review of low level laser therapy with locationspecific doses for pain from chronic joint disorders. Aust. J. Physiother., 49(2): 10716.

Bookhout, M.R. 1996. Exercise and somatic dysfunction. Phys. Med. Rehabil. Clinics of North America. 7: 845-62.

Bookhout, M.R. 1997. Exercise as an adjunct to manual medicine. Handout and lecture presented in Ann. Arbor., MI.

Cherkin, D.C., Eisenberg, D., Sherman, K.J., Barlow, W., Kaptchuk, T.J., Street, J., Deyo, R.A. 2001. Randomized trial comparing traditional Chinese medical acupuncture, therapeutic massage, and self-care education for chronic low back pain. Arch. Intern. Med, 161(8): 1081-8.

Cherkin, D.C., Sherman, K.J., Deyo, R.A., Shekelle, P.G. 2003. A review of the evidence for the effectiveness, safety, and cost of acupuncture, massage therapy, and spinal manipulation for back pain. Ann. Intern. Med., 138(11): 898-906.

Chiradejnant, A., Maher, C.G., Latimer, J., Stepkovitch, N. 2003. Efficacy of "therapist selected" versus "randomly selected" mobilisation techniques for the treatment of low back pain: a randomised controlled trial. Aust. J. Physiother., 49(4): 233-41.16. CMAJ (Oct 2004).

Domjan, L., Nemes, T., Balint, G.P., Toth, Z., Gomor, B. 1990. A simple method for measuring lateral flexion of the dorsolumbar spine. J. Rheumatol., 17: 663-665.

Donald, D. Price, Patricia A. McGrath, Amir Rafii and Barbara Buckingham. 1983. The validation of visual analogue scales as ratio scale measures for chronic and experimental pain. Pain, 17(1): 45-63.

Furlan, A.D., Brosseau, L., Imamura, M., Irvin, E. 2002. Massage for low-back pain: a systematic review within the framework of the Cochrane Collaboration Back Review Group. Spine, 27(17): 1896-910.

Ganong: A Text Book Of Medical Physiology, Ed3, Philadelphia, 1968, WB Sauders. A 
manual of reflexive therapy of the connective tissue, Scarsdale, NY, 1978, Sidney.

Gert Bronfort, Mitchell Haas, Roni L. Evans, , Lex M. Bouter, 2004. Efficacy of spinal manipulation and mobilization for low back pain and neck pain: a systematic review and best evidence synthesis; The Spine Journal, 4(3): 335-356.

Greenman, P.E. 1996. Principles of manual medicine, 2nd ed. Baltimore: Williams and Wilkins,

Grieve, G.P. 1981: Vertebral joint problems, New York,. 1ST ed,Churchill Livingstone.

Grönblad, M., Hurri, H., Kouri, J.P. 1997. Relationships between spinal mobility, physical performance tests, pain intensity and disability assessments in chronic low back pain patients. Scandinavian Journal of Rehabilitation Medicine, 29(1): 17-24.

Andersson, Gunnar, Stephen, L. Demeter, George Smith, M. 1996. American academy of orthopedic surgeons: Manual for orthopedic surgeons in evaluating permanent physical impairment. Chicago, Illinois, 1-30.

Hart, L.G., Deyo, R.A., Cherkin, D.C. 1995. Physician office visits for low back pain: frequency, clinical evaluation, and treatment patterns from a U.S. national survey. Spine, 20: $11-9$.

Hagen, E.M., Eriksen, H.R., Ursin, H. 2000. Does early intervention with a light mobilization program reduce long-term sick leave for low back pain? Spine, 25(15): 1973-6.

Harvey, E., Burton, A.K., Klaber, Moffett, J, Breen, A 2003. Spinal manipulation for low back pain: a treatment package agreed by the UK chiropractic, osteopathy and physiotherapy professional associations. Manual Therapy, 8: 46-51.

Hazard, R.G. 1996. Chronic low back pain and disability: The efficacy of functional restoration. Bull. Hosp. Joint Dis., 55: 2136.

Helene M., Langevin, Karen Sherman, J. 2006. Pathophysiological model for chronic low back pain integrating connective tissue and nervous system mechanisms Elsevier, 06.033.

Hemmila, H.M., Keinanen-Kiukaanniemi, S.M., Levoska, S., Puska, P. 2002. Longterm effectiveness of bone-setting, light exercise therapy, and physiotherapy for prolonged back pain: a randomized controlled trial. $J$. Manipulative Physiol. Ther., 25(2): 99-104.

Jette, A. 2006. Toward a common language for function, disability, and health. Phys. The., 86(5): 726-734,

Jousset, N., Fanello, S., Bontoux, L., Dubus, V., Billabert, C., Vielle, B., Roquelaure, Y., Penneau-Fontbonne, D., Richard, I. 2004. Effects of functional restoration versus 3 hours per week physical therapy: a randomized controlled study. Spine, 29(5): 487- 93.

Keller, R.B., Atlas, S.J., Soule, D.N., Singer, D.E., Deyo, R.A. 1999. Relationship between rates and outcomes of operative treatment for lumbar disc herniation and spinal stenosis. J. Bone Joint Surg. Am., 81: 752-62.

Fisher, K. \& Johnston, M. 1997. Validation of the Oswestry Low Back Pain Disability Questionnaire, its sensitivity as a measure of change following treatment and its relationship with other aspects of the chronic pain experience Physiotherapy Theory and Practice, 13(1): 67-80.

Kovacs, Francisco, M., Abraira, Víctor, Zamora, Javier, Teresa, Gil del Real, María, Llobera, Joan, Fernández, Carmen. 2004. Correlation Between Pain, Disability, and Quality of Life in Patients With Common Low Back Pain; Spine, 29(2): 206-210.

Kuukkanen, T., Malkia, E. 2000. .Effects of a three-month therapeutic exercise programme on flexibility in subjects with low back pain. Physiother. Res. Int., 5(1): 46- 61.

Licciardone, J.C., Stoll, S.T., Fulda, K.G., Russo, D.P., Siu, J., Winn, W., Swift, J., Jr. 2003. Osteopathic manipulative treatment for chronic low back pain: a randomized controlled trial. Spine, 28(13): 1355-62.

Liddle, S.D., Baxter, G.D., Gracey, J.H. 2004. Exercise and chronic low back pain: what works? Pain, 107(1-2): 176-90.

Lucie, Milne, Sarah, Robinson, Vivian, M., Marchand, Serge, Shea, Beverley; Wells, George; Tugwell, Peter. 1991. Efficacy of the Transcutaneous Electrical Nerve Stimulation for the Treatment of Chronic Low Back Pain: A Meta-Analysis, Pain, 47(1): 53-63. 
Lund, J.P., Donga, R., Widmer, C.G., Stohler, C.S. 1991. The pain adaptation model: a discussion of the relationship between chronic musculoskeletal pain and motor activity. Can. J. Physiol. Pharmacol., 69(5): 683-94.

Macrae IF, Wright V. 1969. Measurement of back movement. Ann. Rheum. Dis., 28: 584-589.

Mannion, A.F., Taimela, S., Muntener, M., Dvorak, J. 2001. Active therapy for chronic low back pain part 1 . Effects on back muscle activation, fatigability, and strength. Spine, 26(8): 897-908.

Davidson, M. and Jennifer, L. Keating. 2002. A Comparison of Five Low Back Disability Questionnaires: Reliability and Responsiveness. Physical Therapy, 82(1): 824.

Michael, E. Geisser, Elizabeth A. Wiggert, Andrew J. Haig, M.D., Miles, O. Colwell, 2005. A Randomized Controlled Trial Of Manual Therapy And Specific Adjuvant Exercise For Chronic Low Back Pain Clin. J. Pain,. 21(6): 463-470.

Moseley, L. 2002. Combined physiotherapy and education is efficacious for chronic low back pain. Aust. J. Physiother, 48(4): 297-302.

Niemisto, L., Lahtinen-Suopanki, T., Rissanen, P., Lindgren, K.A., Sarna, S., Hurri, H. 2003. A randomized trial of combined manipulation, stabilizing exercises, and physician consultation compared to physician consultation alone for chronic low back pain. Spine, 28(19): 2185-91.

Petersen, T., Kryger, P., Ekdahl, C., Olsen, S., Jacobsen, S. 2002 .The effect of McKenzie therapy as compared with that of intensive strengthening training for the treatment of patients with subacute or chronic low back pain: A randomized controlled trial. Spine, 27(16): 1702-9.

Pustaver, M.R. and Mathews. 1995. Etiology and conservative management of mechanical low back pain J. Manipulative Physiol. Ther., 18(6): 419.

Richard, A., Deyo, James, Weinstein, N. 2001. Primary care, low back pain, N. Engl. J. Med, 344( 5): 363-370.
Roland, M.O. 1986. A critical review of the evidence for a pain-spasm-pain cycle in spinal disorders. Clin. Biomech., 1(2): 1029.

Rosomoff, H.L., Fishbain, D.A., Goldberg, M., Santana, R., Rosomoff, R.S. 1989. Physical findings in patients with chronic intractable benign pain of the neck and/or back. Pain., 37: 279-87.

Sahrman, S.A. 2002. Diagnosis and treatment of movement impairment syndromes. St. Louis: Mosby.

Scott, F., Nadler, Kurt Weingand, and Roger, J. Kruse; 2004. The Physiologic Basis and Clinical Applications of Cryotherapy and Thermotherapy for the Pain Practitioner; Pain Physician., 7: 395-399.

Serge Marchand, a, Jacques Charesta, Jinxue Lia, Jean-René Chenarda, Benoit Lavignolleb and Louis Laurencellec Is TENS purely a placebo effect? A controlled study on chronic low back pain 2003.

Swedlow, A.,, Johnson G., Smithline, N., Milstein, A. 1992. Increased costs and rates of use in the California workers' compensation system as a result of selfreferral by physicians. $N$. Engl. J. Med., 327: $1502-6$.

Sweetman, B.J., Heinrich, I., Anderson J.A.D 1993. A randomized controlled trial of exercises, short wave diathermy, and traction for low back pain, with evidence of diagnosis-related response to treatment. $J$. Orthopaedic-Rheumatology, 6: 159-66.

Walach, H., Guthlin, C., Konig, M. 2003. Efficacy of massage therapy in chronic pain: a pragmatic randomized trial. J. Altern. Complement. Med., 9(6): 837-46.

Warwick, R., Williams, P. 1973. Gray's anatomy. Philadelphia, Saunders.

Werners, R., Pynsent, P.B., Bulstrode, C.J. 1999. Randomized trial comparing interferential therapy with motorized lumbar traction and massage in the management of low back pain in a primary care setting. Spine, $\mathbf{2 4 ( 1 5 ) :}$ 1579-84. 